\title{
Policy Constraints And Strategic Choices: MNE Subsidiaries' Market Penetration In China
}

Jifu Wang, University of Houston-Victoria, USA

Ronald J. Salazar, University of Houston-Victoria, USA

Joseph Ben-Ur, University of Houston-Victoria, USA

\begin{abstract}
This study describes how firm level decisions and capabilities correspond to policy conditions in a host country where local market access is constrained and success is contingent on compliance with cultural hegemony. Using data from surveys gathered from multinational enterprise (MNE) subsidiaries operating in China, we describe the mode of entry the firms have used to penetrate and exploit markets in light of the constrained strategic choices open to their subsidiaries. We also expose the patterns of growth accomplished by the MNE and their underlying bases of competitive advantage. Finally, we relate the degree of centralization we observe among the respondents' strategies.
\end{abstract}

Keywords: Cultural Hegemony; MNE Subsidiary; China; Strategic Choice

\section{INTRODUCTION}

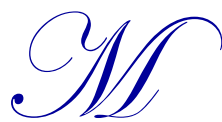

NE business executives experience challenges from more complex and competing forces when host country policy changes encourage the MNE to transfer more of its firm-specific core competences and the political environment encourages MNE subsidiaries to become innovation hubs for surrounding local or regional businesses. Among the many causes of financial crises has been conflicting policy objectives imposed on managers (Laeven \& Valencia, 2012). Such consequences of cultural hegemony are the subject of critical cultural inquiry (Horkheimer, 1937; Castro-Gomez, 2001). Using a critical inquiry lens, we suggest that a pre-dominating focus on the transfer of global technology and on its reengineering is likely to undermine the visibility and the prospects of original innovations rooted in the realities of the local culture and context.

In 2006, Chinese government explicitly embraced indigenous innovation as the developmental pathway, focusing on creating an enabling environment for autonomous locally-embedded innovations (Atkinson, 2012). To achieve the aim of uplifting indigenous innovation capacity, Chinese government put primary emphasis on 'coinnovation' and 're-innovation' through "assimilating and absorbing" advanced technologies transferred by the MNEs (McGregor, 2010). Since local innovations are seen as contingent on the transfer of MNE's firm-specific advantages, the subsidiaries are likely to find it difficult to fully leverage and link country-specific advantages with the complex firm-specific advantages, and therefore the innovations are likely to be oriented towards shallow adaptation of the foreign technology to the local situation. By putting a primary emphasis on the transfer of foreign know-how, one unintended consequence will be that the local potential to develop innovative technological trajectories embedded in the country-specific advantages is discredited and subordinated.

Based on the insights from the theory of organizational imprinting (Johnson, 2012), it is likely that in a policy context where local market access is constrained and the constraints are only gradually eased contingent on transferring upgraded technologies, the organizational culture and orientation of the MNE subsidiaries will be, in part, shaped by the initial strategy of giving primacy to the technological platforms and organizational approaches of 
the parent company. When success in doing so opens access to the local market, the subsidiaries might continue to demonstrate a high level of path dependency. Instead of pursuing innovations with an open mindset, they might continue to deploy hierarchical and application-oriented approaches rooted in the earlier organizational paradigm and only shallow adaptation to the local demand context. Thus, their research and manufacturing might continue to be centralized and leadership in the human resource and the complex marketing roles continue to be centralized as well; only lower-level human resource and more tactical and generic marketing roles might be decentralized. If this occurs, the subsidiaries will be vulnerable to deep weaknesses and overlooking deep opportunities because of a misalignment particularly of their human resource and marketing functions (where a high level of local responsiveness is expected) to their strategic realities. Yet, they might hold socially constructed surface perceptions of strengths and opportunities - if the parental firm-specific advantages may allow them to contest market share from the local competitors with comparative ease. The real potential for deeper capabilities and for deeper opportunities rooted in the popular grassroots culture may remain latent, hidden and invisible, and gradually be lost, assimilated, and subordinated to the institutionally legitimated and enforced alien foreign culture.

In the existing literature, there is little discussion of the relationship between market access and strategic choice. In our earlier paper (Salazar, et al, 2011), we laid the foundation for how policy would likely influence technology adoption. Now we describe the strategic choices themselves. Recently, Dongli (2013) studied the performance impacts of increased vertical integration, for example, but did so within a stable policy context. The concept of 'strategic choice' typically includes not only the establishment of structural forms but also the manipulation of environmental forces (Child, 1972). This study examines a context wherein cultural hegemony enforces market constraints and influences choice. Studies of increasing returns demonstrate that in a context of scale-intensive production, constrained market access will increase cost structure (Krugman, 1991). The process of adapting to the high-cost situation under constrained market access will undermine the development less costsensitive capabilities. Similarly, the post-hoc and uncertain nature of the liberal market access will impede deep adaptation and inhibit the development of differentiation-sensitive capabilities. Thus, we expect tensions between the export-oriented development and the deepening of Chinese capabilities for moving into a higher technology, higher skilled frontier. The tensions between these two goals can produce instabilities as the government is forced to offer concessions in the form of access to local markets to achieve the second objective and as the policy of constraints and concessions create macroeconomic destabilization and contributes to inflationary pressures.

Next, we discuss our sample and data on the MNE subsidiaries in China. We then present our findings related to the mode and sequence of entry, growth and development patterns, bases of competitive advantage, degree of centralization, and research and development. Finally, we discuss the major implications of our findings. Broadly, our study shows how micro-level decisions and capabilities respond to the macro policy where local market access is constrained and contingent on transferring upgraded technologies. Based on our empirical data and discussion based on our findings, we show that the MNEs develop strategies that consider both export potential and local market potential, even if the local market potential may be initially constrained.

\section{LITERATURE REVIEW}

The review of global strategy literature for MNE generally presents a trade-off between an emphasis on the firm-specific advantages of the MNEs and their reliance on the local country-embedded innovations. An interesting trend indicated that MNEs tend to focus either on global integration for exploiting firm-specific core competences or on local autonomy for tapping locally embedded benefits. The degree of centralization by the parent MNEs varies upon the type of advantage exploited. Mjoen \& Tallman (1997) indicated that MNE centralization has generally produced no discernible negative impact on their foreign subsidiaries. Studies of Chinese subsidiaries reported positive relationship between the two because of parents' firm-specific advantages. From a transaction cost perspective, higher firm specific advantage tends to prevent unintentionally technology spillage to a local partner (Williamson, 1985). Other studies reported a negative relationship (Beamish, 1993) because of the need for the sampled subsidiaries to have greater local autonomy in achieving country-specific advantages in China.

Some studies have shown that a global strategy might moderate the interaction between centralization and the subsidiary performance (Doz \& Prahalad, 1994). When MNEs pursue a globally integrated strategy, they tend to place more emphasis on MNE's global network advantages so that the MNEs can obtain better control subsidiary 
activities in developing and leveraging network competitive advantages. On the other hand, when MNEs pursue a more locally responsive strategy, they are placing more on the subsidiary's local competitive edge. As a result, MNEs may offer higher degree of autonomy to the subsidiaries to achieve the local leverage and maintain better competitive positions over their rivals. Bartlett (1986) used the two-dimension research framework (globalization pressure vs. local pressure) to advance three types of multinational corporations - global, multinational and transnational organizations. In 1986, Bartlett and Ghoshal further developed the three-quadrant model by Stopford and Wells and replaced the original three-quadrant model by the four-quadrant model, using low reaction and low integration in the contingency presentation (see Figure 1).

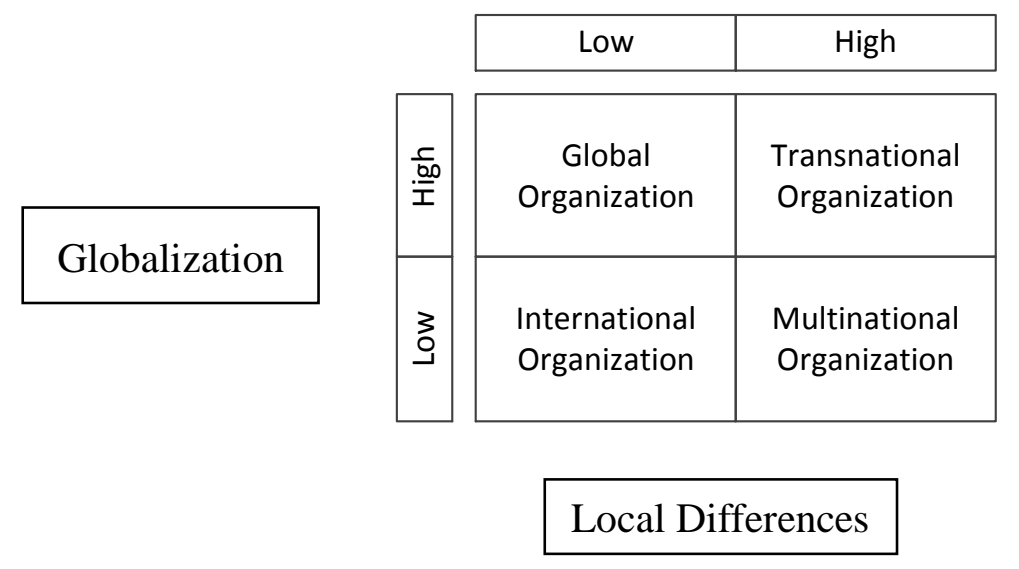

Figure 1: Expansion Motivation

When cultural distance (CD) between the parent MNE and the local country is high, it is more difficult to pursue global integration (Fan, Zhu \& Nyland, 2012). Multiple research results indicated that the higher the CD, the more control the MNE was likely to maintain over its foreign operations (Root, 1987; Davidson and McFeteridge, 1985; Kim and Hwang, 1992). Cultural distance has great impact on the ability of the MNEs in the process of global integration. However, institutional constraints are likely to moderate this relationship. The Chinese policy permits the entry of MNEs if they agree to transfer their technology, organizational and management know-how. Culture distance influences the mode of entry choices when the MNEs perceiver high cultural distance; they are more likely to rely on joint ventures (Kogut \& Singh, 1988) because local partners can act as cultural informants for the MNEs (Fortier \& El Hadrioui, 2012) and allow the MNEs to offer some autonomy to their subsidiaries to best exploit local resources and to best respond to the local contingencies.

MNEs do not follow a strategy that is completely from centralization or completely from local autonomy because, in reality, certain functions are more centralized but others are more decentralized. The Chinese government policy encourages MNEs to transfer their advanced firm-specific advantages. For research and manufacturing, the MNE institutional adaptation reaction should embrace greater control of these functions because of the need to be consistent with the strategic demands to assure increasing returns. The Chinese government policy also seeks a willingness to swap access to local Chinese market in exchange for the transfer of advanced technology (Deng, Falvey, \& Blake, 2010), which would result in greater decentralization in exploiting the local access.

Many scholars have tried to identify the roles of overseas subsidiaries using different perspectives (Bartlett and Ghoshal, 1986; Jarillo and Martinez, 1990; Gupta and Govindarajan, 1991; Taggart, 1996). As each of the subsidiaries is established by the MNEs in specific circumstances, each has a specific strategic task within in the MNE network.

The role assigned to the subsidiary within the MNE's global value chain is also likely to moderate the relationship between the degree of centralization and the subsidiary performance. Generally speaking, all the following elements can cause the adjustment of initial role of the subsidiaries - the evolution of the global strategy of parent company, the environment of the host country, and the development target of overseas subsidiaries themselves. The first two elements cause the passive adjustment of the role of subsidiaries, while the development target of overseas subsidiaries cause the active adjustment of the role of subsidiaries. 
Professor Mao Yunshi (1997) discovered that the first two investment motivations of foreign companies are "low labor cost" and "guarantee the quality of the product and the service". The roles of the MNE subsidiaries in China are evolving from production-based to market-pioneer (Robinson, et al, 1992) based. The main reason for this trend is the switch of the investment motivation of the MNES' subsidiaries in China.

White and Poynter (1984) have identified two categories of subsidiary roles: one is a mixed copy of the parent MNE, where the subsidiaries are miniature replicas who replicate or adapt the MNE product and marketing plan in the local market, and the second is a rational manufacturer that produces parts or finished products for a multi-country market or functions as an off-shore center for downstream global value chain.

\section{METHODOLOGY}

The sampled companies for this study were MNE subsidiaries in China (Table 1). A total of 400 survey questionnaires were mailed to managers in more than thirty Chinese cities. If the subsidiary was the result of a joint venture, we surveyed executives from the foreign holding firm, as well as the Chinese partner, to validate acquired information. Follow up telephone calls and e-mails were employed to encourage participation.

A total of 150 questionnaires were returned for a response rate of $38 \%$. Of those returned, 22 questionnaires were incomplete and therefore unusable, resulting in a sample of 128 firms. Of these MNE's, 28 (21.9\%) were US subsidiaries, $22(17.2 \%)$ were Japanese, 25 (19.5\%) were from European Union countries, 43 $(33.6 \%)$ were South Korean, and the remaining $8(7.8 \%)$ firms were from a variety of other countries.

Table 1: The Sample

\begin{tabular}{|c|c|c|c|}
\hline Firm Characteristics & Firm Category & $\mathbf{N}$ & Percentage $(\%)$ \\
\hline \multirow{11}{*}{ Country Origin } & South Korea & 43 & 33.6 \\
\hline & USA & 28 & 21.9 \\
\hline & European Union & 25 & 19.5 \\
\hline & Japan & 22 & 17.2 \\
\hline & Others & 10 & 7.8 \\
\hline & Singapore & 4 & 3.1 \\
\hline & Thailand & 2 & 1.6 \\
\hline & Australia & 1 & 0.8 \\
\hline & Canada & 1 & 0.8 \\
\hline & Malaysia & 1 & 0.8 \\
\hline & Swiss & 1 & 0.8 \\
\hline \multirow{3}{*}{ Firm Nature } & Foreign Owned & 91 & 71.1 \\
\hline & Foreign Holding & 34 & 26.6 \\
\hline & Joint Venture & 3 & 2.3 \\
\hline \multirow{6}{*}{ Headquarters Location } & China Headquarters & 33 & 25.8 \\
\hline & Global Headquarters & 31 & 24.2 \\
\hline & Asia Pacific Headquarters & 27 & 211 \\
\hline & Big China Headquarters & 7 & 5.5 \\
\hline & Missing Data & 17 & 13.3 \\
\hline & Others & 13 & 10.2 \\
\hline \multirow{15}{*}{ Industry } & Electronics & 35 & 27.3 \\
\hline & Textile & 23 & 18.0 \\
\hline & Chemistry and Pharmaceutical & 15 & 11.7 \\
\hline & Iron, Steel, Mechanics and Engineering & 13 & 10.2 \\
\hline & Auto Manufacturing & 9 & 7.0 \\
\hline & Food and Beverages & 9 & 7.0 \\
\hline & Commerce and Trade & 7 & 5.5 \\
\hline & Transportation & 5 & 3.9 \\
\hline & Tele-Communications & 3 & 2.3 \\
\hline & Finance and Insurance & 2 & 1.6 \\
\hline & Consulting & 2 & 1.6 \\
\hline & Others & 2 & 1.6 \\
\hline & Gasoline and Mining & 1 & 0.8 \\
\hline & Real Estate & 1 & 0.8 \\
\hline & Mass Communication & 1 & 0.8 \\
\hline
\end{tabular}


Table 1 cont.

\begin{tabular}{|c|c|c|c|}
\hline Respondent Categories & $\begin{array}{c}\text { Board Chairman } \\
\text { Board Vice Chairman } \\
\text { Board Members } \\
\text { CEO } \\
\text { Vice CEO } \\
\text { Department Manager } \\
\text { Others } \\
\text { Missing Data }\end{array}$ & $\begin{array}{c}3 \\
4 \\
6 \\
13 \\
16 \\
46 \\
31 \\
9\end{array}$ & $\begin{array}{c}2.3 \\
3.1 \\
4.7 \\
10.2 \\
12.5 \\
35.9 \\
24.2 \\
7.0\end{array}$ \\
\hline Firm Age & $\begin{array}{c}\text { Less than } 5 \text { years } \\
5-9 \text { years } \\
10-15 \text { years } \\
\text { More than } 15 \text { years } \\
\text { Missing data }\end{array}$ & $\begin{array}{c}43 \\
49 \\
22 \\
10 \\
4\end{array}$ & $\begin{array}{c}33.6 \\
38.3 \\
17.2 \\
7.8 \\
3.1\end{array}$ \\
\hline
\end{tabular}

\section{RESULTS}

Cheap natural resources and an available, low cost labor forces were the reason why $95 \%$ of respondents selected market exploration and production as the primary role of the subsidiary. In fact, $97.8 \%$ of all the production-based subsidiaries mentioned cheap labor as a motivating factor, suggesting that much of China's Foreign Direct Investment (FDI) followed an external market/factor-seeking motivation. Profit maximization was the primary reason for FDI and was the market motivator for MNEs but was not acknowledged as a reason for entrance into the Chinese marketplace even though the ability of an MNE to maximize profit has long been considered an important reason for international expansion (Cohen \& Rugman, 1976).

\section{Mode of Entry}

Generally, Western MNEs perceive a high degree of cultural distance in China, which makes entry modes based on moderate commitment generally more appropriate, such as joint ventures. Such entry modes rely more on the local participation as a way to benefit from the resources, networks, and knowledge of the local partners, and to adapt to the local cultural and institutional context. In contrast, the East Asian MNEs perceive a lower degree of cultural distance in China, making entry modes based on high commitment, such as wholly owned subsidiaries, more appropriate. Such entry modes allow the MNEs to better integrate local operations with their home and global operations because of a greater expectation of fit between their organizational structure, routines, and culture with the local context.

In general, the MNEs surveyed do not favor acquisitions as their mode of entry into China. In our sample, only $5.1 \%$ of the MNEs entered China through partial or full acquisition. The Chinese government policy concerning foreign acquisition was vague and involved complicated procedures and documentation, along with restrictions within some industries and on the proportion of foreign equity holding. Moreover, the overall initial quality and capabilities of domestic firms was relatively weak and were not perceived to complement the MNE growth strategy and add value to MNE core competences. A few MNEs who pursued acquisitions were motivated primarily by rapid entry of Chinese markets and the shorter time required to reach acceptably efficient levels of local productivity. Knowledge access, management personnel access, or funding access, were not shown to be significant by among respondents respondent.

From Table 2, we can see that chi-square value is 10.594 with significance level of 0.05 and the probability $\mathrm{P}$ value of 0.014 , which is less than $\alpha$. We can see from the Kruskal-Wallis Test that the ways of investing by the subsidiaries of multinational companies from different country origins were significantly different when they first entered the Chinese market.

Table 2: Sample Statistics

\begin{tabular}{|l|c|c|c|}
\hline & $\chi^{2}$ & df & P value \\
\hline Initial Entry of Investment & 10.594 & 3 & 0.014 \\
\hline Effective Sample & 114 & & \\
\hline
\end{tabular}


We tested the hypothesis that Western MNEs are more likely to use joint ventures as a mode of entry, while the East Asian MNEs are more likely to use wholly-owned subsidiaries as a mode of entry. As shown in Table 3, our findings are consistent with this hypothesis. The entry mode is correlated with the parental MNE national origin: $\chi^{2}$ $(3, \underline{N}=114)=10.594, p<0.05$.

Table 3: Sample Entry Mode Type and Ownership

\begin{tabular}{|c|c|c|c|c|}
\hline Entry Mode & $\mathbf{U S}$ & Japan & $\mathbf{E U}$ & Korea \\
\hline New wholly foreign owned firms & 12 & 13 & 11 & 33 \\
\hline New joint ventures & 11 & 7 & 11 & 7 \\
\hline Wholly foreign owned firms through acquisition & 0 & 1 & 1 & 1 \\
\hline Joint venture through acquisition or merger & 2 & 0 & 1 & 0 \\
\hline
\end{tabular}

Our findings also show (Table 4) that multinational firms from the United States and the EU were similar in their initial investment modes and in entry forms of new wholly foreign owned firms and new joint adventures. However, the entry forms for firms from Japan and South Korea were significantly different than those for firms from the US and European Union. When firms from South Korea and Japan first entered the Chinese market, they preferred wholly foreign-owned firms to new joint ventures. The motives for additional direct investment reflected the MNE strategic intentions for MNE subsidiaries in China. Therefore, study on investment motives is of particular importance in this research. We verified our assumptions and inferences on the overriding motive for additional investment into MNE subsidiaries in China, which is to expand production base and realize the maximized profits from China growth potentials.

Table 4: Sample Investment Motivation

\begin{tabular}{|l|c|c|c|}
\hline \multicolumn{1}{|c|}{ Investment Motives } & Samples & Mean & Standard Deviation \\
\hline China's economic growth optimistic expectations & 104 & 4.08 & 1.040 \\
\hline Seeking maximized profits & 95 & 4.03 & 1.005 \\
\hline Expanding production bases in China & 94 & 3.87 & 1.008 \\
\hline Expanding market share in China & 91 & 3.87 & .991 \\
\hline Investment environment stability in China & 104 & 3.84 & 1.006 \\
\hline Sustaining low-cost advantages & 89 & 3.78 & 1.085 \\
\hline Competing global competitors & 78 & 3.44 & 1.180 \\
\hline Enhancing R\&D capabilities in China & 80 & 3.36 & 1.058 \\
\hline Following existing clients & 81 & 3.31 & 1.261 \\
\hline
\end{tabular}

Having analyzed the results of the frequency test on this topic from the data of our questionnaire, we ranked the MNE investment motives in China as shown in Table 5. Our results suggest most respondents believed that China has great potential in its market growth and wanted to realize the greatest profits. Economic optimism thus informed the strategic motives shown in the table.

Table 5: Ordered Investment Motivation

\begin{tabular}{|l|c|c|c|}
\hline \multicolumn{1}{|c|}{ Strategic Motive } & Samples & Mean & Standard Deviation \\
\hline Seeking maximized profits & 95 & 4.03 & 1.005 \\
\hline Expanding production bases in China & 94 & 3.87 & 1.008 \\
\hline Expanding market share in China & 91 & 3.87 & .991 \\
\hline Sustaining low-cost advantages & 89 & 3.78 & 1.085 \\
\hline Competing global competitors & 78 & 3.44 & 1.180 \\
\hline Enhancing R\&D capabilities in China & 80 & 3.36 & 1.058 \\
\hline Following existing clients & 81 & 3.31 & 1.261 \\
\hline
\end{tabular}

\section{Growth Patterns Observed}

We can further report that sales, investment scale, and market share have propelled the growth momentum for MNE subsidiaries in China. We have identified three reasons for this strong momentum. First, MNE subsidiaries in China are in the growth stage or just getting started in the Chinese market. Establishing a corporate image, strengthen the branding effects and expand sales channels requires a great deal of local talent and requires a 
large amount of capital investment. Second, consider China's huge market potential. MNE subsidiaries in China are engaging in expanding production base and sales to gain market share. Their strategic priority is not on the pursuit of profit or rate of return on investments at this time. Third, the parent companies of multinational corporations assess the performance of subsidiaries using such indicators as sales volume, investment scale, and market share. These appraisal indicators affect the management decision choices and operation activities of the subsidiaries in China. We discovered two different behaviors of the subsidiaries.

The results we observe in Table 6 indicate that the two most important growth indicators for MNE subsidiaries in China are sales volume, investment scale, and market share. The mean scores were 3.77, 3.67, and 3.61, respectively, which were much higher than those for other indicators. Sample firm consensus rate on three important drivers reached $63.3 \%, 60.4 \%$ and $54.1 \%$, respectively. Most of the executives in this study agreed that sales volumes, investment scale, and market shares are three most important indicators for subsidiary growth.

Table 6: Drivers of Growth

\begin{tabular}{|l|c|c|c|c|}
\hline \multicolumn{1}{|c|}{ Growth Drivers } & Sample Size & Mean & Standard Deviation & Sample Consensus \% for Significance \\
\hline Sales volume & 109 & 3.77 & 0.878 & 63.3 \\
\hline Investment scale & 96 & 3.67 & 0.842 & 60.4 \\
\hline Market shares & 96 & 3.61 & 0.875 & 54.1 \\
\hline Profit & 110 & 3.31 & 0.916 & 48.1 \\
\hline Return on investment & 92 & 3.24 & 0.839 & 43.5 \\
\hline R\&D investment & 82 & 3.22 & 0.893 & 37.8 \\
\hline
\end{tabular}

Of course, sales volumes, investment scale, and market share are not only the concerns of the MNE parent companies, but they seem to serve as a necessary conditions for the survival of the MNE subsidiaries in their emerging phase or at the early stage of the growth phase. We found that the parent companies show less concern for the research and development of their subsidiaries because of the relatively large funding without much promise of short term results. We found two reasons for this phenomenon. First, these performance indicators are easy to measure and recognize. To survive, grow, and meet the parent company expectations, the subsidiaries have invested tremendously in these areas, both in money and human capital. Subsidiaries exhibiting poor sales volume and market share results will often face serious consequences of getting less support from the parent company and have great risk of being merged or acquired, or even sold off. The most typical case was Whirlpool, which acquired Snowflakes Appliances with an investment of $\$ 30$ million. Because the subsidiary did not meet Whirlpool's expectations in sales and market performance, it was sold for only $\$ 2$ million when withdrawing from the China market. Dutch dairy giant Friesland Kraft Parmalat was another withdrawal case. Before entering the Chinese market, these firms planned to make profit by the sixth year, but when their subsidiaries in China suffered losses for nine consecutive years with stagnating sales and unsatisfactory market share, they withdrew. In the end, they decided to divest and withdraw from the Chinese market at a huge loss. Later, they all regretted such a short-sighted choice when they saw their competitors got the market leadership positions and scanned the market with huge gains. Secondly, at the entry stage, multinational companies postponed research and development spending for their subsidiaries for two reasons: 1) Research and development indicators are not easily measured and evaluated and 2) China was relatively weak in scientific research at the time when most MNEs began to invest and they did not yet possess the necessary conditions to become regional research and development centers. Thus, most of the multinational companies had housed their R\&D centers outside China. This greatly hindered the digestion of technological progress for local development and hurt the subsidiaries' long-term growth. Now, many multinational companies have increased research and development expenditures.

\section{Bases of Competitive Advantage}

Western MNE subsidiaries in the favorable strength-opportunity quadrant tended to have a broader base of sources of competitive advantage. We found that the MNE subsidiaries, with a strong competitive position in terms of the relative market share in China - i.e., ratio of the firm's market share and the market share of a dominant competitor - reported superior competitive advantages in product, service, customer relationship, quality, logistics, core technology, and R\&D capability. 
Because of their stronger connectivity with the advanced value chain in the parent home nation, Japanese MNE subsidiaries in the strength-threat quadrant tended to have a moderate, but somewhat lower base of competitive advantage sources. Finally, because of their stronger exposure to the distributed global markets, Korean MNE subsidiaries in the weakness-opportunity quadrant had the weakest base of competitive advantage sources. Given the focus of the Chinese vendors and competitors on cost-oriented factors, perceptions of strength are likely to be correlated with a broad emphasis on differentiation, such as through diversified product portfolio and corporate image. We found that MNE subsidiaries in China rely on local strategic alliances with procurement cost reduction as a primary motivation (more than $75 \%$ rated it significant). Furthermore, MNE subsidiaries in China had high awareness of the need and procedures to enhance customer satisfaction, improve corporate image, implement customer relationship management and service assurance so that firms could get closer to their customer and improve the company's image in the marketing strategy. This customer service orientation of MNE subsidiaries in China gave them competitive advantage over the product-centric manufacturing and sales push orientation common among Chinese state-owned enterprises - primary competitors in many sectors of the economy. Customer serviceorientation helped MNE subsidiaries in China re-design their marketing strategy to reduce costs while improving the service quality by focusing on enhancing the overall firm image rather than on advertising or branding image of individual product. We tested the hypothesis that the MNE subsidiaries in the strength-opportunity quadrant are likely to demonstrate stronger emphasis on broad differentiation (product portfolio, corporate image), followed by those in the strength-threat quadrant. Those in the weakness-opportunity quadrant are likely to demonstrate weakest emphasis on broad differentiation. As shown in Table 7, the data are consistent with this hypothesis.

Table 7: Perceived SWOT Posture

\begin{tabular}{|l|c|c|}
\hline \multicolumn{1}{|c|}{ Variable } & Comparing Groups & Difference \\
\hline \multirow{3}{*}{ Corporate image } & SO-ST & 0.14 \\
\cline { 2 - 3 } & ST-WO & $-0.36^{*}$ \\
\cline { 2 - 3 } & SO-WO & $0.50^{* *}$ \\
\hline \multirow{3}{*}{ Product portfolio } & SO-ST & 0.09 \\
\cline { 2 - 3 } & ST-WO & $1.00^{* *}$ \\
\cline { 2 - 3 } & SO-WO & $1.09 * *$ \\
\hline
\end{tabular}

Note: $* * \mathrm{p}<0.05 ; * \mathrm{p}<0.01$

\section{Degree of Functional Centralization}

The MNEs often pursue localization strategy through decentralization of selected functions. When the activities of relevant functions are not appropriately adapted to the local context, the likelihood of committing costly errors tends to be high. In our research, marketing and human resource functions were most frequently cited areas of strategic blunders by the MNE subsidiaries in China. These were also the functions where the MNEs tended to pursue a higher degree of localization and granted more autonomy to their local Chinese subsidiaries.

In the marketing function, greater emphasis on local markets was correlated with greater autonomy in marketing research and forecasting, choice of target markets, and product-focused advertising, while greater export orientation was correlated with a centralized role by the parent MNE in these areas. These differences were related with the overall strategic emphases by the subsidiaries of different nations on various marketing elements.

In general, the US MNE subsidiaries put a greater priority on market research and forecasting, while the European subsidiaries emphasized product-focused branding. The more export-focused and globally integrated Japanese and South Korean subsidiaries were more concerned about their corporate image for long-term development. Maintaining a robust product portfolio was an important element for all these subsidiaries.

Errors were attributed by the MNE subsidiary executives to the differences in the Chinese culture, lack of resources and support for adequate local adaptation from the parent MNE, and adjustments in corporate strategy, such as increased focus on the local market. More broadly, MNEs were motivated by scale-oriented investment factors - specifically, expanding the Chinese production base, capture market share, and gain or maintain an advantageous cost position. 
China was seen as a global manufacturing hub and the low-cost as an advantage for rapid expansion and to reduce global production costs. MNEs emphasized product quality and brand image in order to differentiate themselves against the local Chinese players who also enjoyed the same low-cost Chinese platform in order to successfully penetrate and satisfy the emerging Chinese market demand. They perceived other MNE subsidiaries in China, who were capable of similar differentiation and who also enjoyed similar cost advantage, to be their closest competitors - not the local Chinese players. In this context, the most important performance measures from the perspective of the MNE parents were revenues and profits, followed by market share, product quality, return on investment, and customer satisfaction.

Human resources, $R \& D$, and social responsibility were of limited importance. With expansion of Chinese market and intensification of scale-based competition, the existing resources and inputs became increasingly insufficient for additional growth to satisfy the global strategy adjustment need of the parent company.

The emphasis on the scale-oriented measures by the Chinese subsidiaries was attributed partly to their ease of measuring, quantifying, and implementation. Therefore, the subsidiaries in China used these appraisal indicators for management decision choices and operation activities. While the parent MNEs were often willing to assume low profitability, low rate of return, and low cost reductions for fairly long periods on the assumption of a long-term commitment to China, they were less benevolent with subsidiaries who demonstrate poor sales volume and market shares.

\section{DISCUSSION AND CONCLUSIONS}

MNEs establish overseas subsidiaries to optimize resource allocation and to maximize profits. The strategic choices the parent makes for its overseas subsidiaries are influenced by public policy goals in host countries. Among MNEs' subsidiaries in China, the choices must satisfy, on one hand, parent performance requirements, and, on the other, must conform to the constrained resources that China provides. According to our survey, the major investment motives of the MNEs' subsidiaries in China include exploring China's market (66.07\%), establishing production bases (55.36\%), seeking profits $(49.11 \%)$, and making use of the cheaper labor force $(43.75 \%)$.

The primary roles assigned to subsidiaries in China are to be low cost production centers for their global value chains and to penetrate the national market. These role mandates vary by the parental MNE origin. Japanese MNEs have assigned their subsidiaries a primary role of exporting the production from China back to the home nation for advanced value addition and then re-export to the global market. Korean MNEs have assigned a primary role of exporting the production to multi-country markets worldwide. The US and European MNEs have assigned a primary role of using the production from China to develop and penetrate Chinese domestic market and a secondary role of supporting value-added production and direct needs of the home base and other global markets.

The policy of the Chinese government has been to offer access to Chinese market as a carrot in order to induce MNEs to share more sophisticated know-how with their Chinese subsidiaries. The general policy perception seems to be that if the MNEs are offered greater access to the Chinese market and are permitted to decimate or acquire the local enterprises, they often function without supporting technological growth of China. The findings of the present research suggest that at least some degree of increased access to Chinese market might actually enable the Chinese subsidiaries to develop new knowledge bases, based on the unique cultural and historical endowments of China, in order for them to compete effectively in the local market. To benefit from these new local knowledge bases, the MNEs are likely to provide greater strategic autonomy to Chinese subsidiaries and, over time, also be willing to more openly share know-how with them as part of a bilateral, or even multilateral, system of knowledge exchange throughout the MNE network. All this might accelerate knowledge transfers into China. In addition, greater participation in the local market is associated with greater participation by the subsidiary in the intersubsidiary knowledge system, which in turn opens a world of new opportunities for the subsidiary. Conversely, when the factories have to serve the fragmented needs of the different, dispersed markets around the world, their weaknesses may be exposed and the opportunity may appear to be overwhelming, leading to labor confrontation, as evidenced by the experiences of the Korean MNEs. 
Multinational corporations attempting to establish powerful, local control face intense competition in the host environment and find it both time and cost consuming. Multinational corporations must be well aware of this challenge when they make their choices on entry model, strategic objectives, and business evaluations for their subsidiaries.

Without access to the local market, some global factories may be optimized to a sub-optimal scale and not benefit from sufficient deepening of the cost sensitive capabilities. The results may be cost-push, as well as unfilled demand inflation, which may further weaken the cost effectiveness of those operations and result in losses and revenue stagnation and forced withdrawal. When an export-oriented factory is financially troubled, the government is forced to lure the foreign MNEs through a variety of tax concessions. When these tax concessions also do not work, then the government is forced to react by offering concessional local loans and also offer access to the local market.

Many Western MNEs, who entered China with a view of China as the world factory, have found it necessary to adjust their global strategy and focus more on the Chinese domestic market. The exception may be when the Chinese factories are intended to serve highly specialized needs that are in low demand within China. This is akin to the Japanese case where the MNEs use Chinese base as off-shore linkage into their more complex valueadding home operations and therefore connect it to the local operations in the home innovation network to give greater emphasis to innovations by their Chinese subsidiaries. However, in this case, the environment appears more threatening because of the accentuated dependencies on the parent MNE, idiosyncrasies of innovations, and limited flexibility.

Our findings suggest that Chinese subsidiaries have not yet built deep levels of marketing capabilities. Constrained openness of the Chinese markets has resulted in lower attention paid to the development of deeper marketing capabilities that are associated with adapting to the local market conditions. Without deeper marketing capability, the nature of local marketing decisions tends to focus on identifying target markets, forecasting demand, and pushing products through advertising, rather than on brand management and product development. Similarly, in HRM, more freedom is given to local decision-making; however, expatriates dominate the senior positions and without local role models in the senior positions, the motivation and the opportunities for skill development and for authentic local approaches are likely to be constrained. The Western MNEs who have achieved high levels of penetration into the Chinese market tend to demonstrate a broader base of subsidiary competitive advantages, followed by the Japanese MNEs who have integrated Chinese low-cost production base with their additional value adding high-end production base in Japan. The Korean MNEs who use the Chinese low-cost production base for serving different markets globally actually demonstrate very narrow level of subsidiary competitive advantage. In order to compete effectively in the Chinese market, the local subsidiaries need to have stronger and broader competitive advantage over their competitors. The intended locus of this competitive advantage is primarily broad level of differentiation - corporate image and product portfolio - but it has also produced an advantage in other functions that help to compete on the basis of service orientation. Finally, it is notable that for the MNEs seeking to participate in the local market, joint ventures act as an important mechanism for learning and relation building; however, most joint venture partners in China have global ambitions and appear to prefer the MNEs globally integrated strategy that gives them access to the global best practices and that leaves the local market for them. In order to serve the interests of both the MNE and the local partner, these joint ventures might be considered a lab for synergistic learning and innovation. They may be complemented with separate and autonomous operations of both parties for serving their respective global ambitions.

\section{AUTHOR INFORMATION}

Jifu Wang (Ph.D. from Auburn University) is an associate professor at University of Houston, Victoria. He is the chairman of Lanfu Global LLC and was the president of US Genesis Global Capital. He served as an executive in top management teams for several group companies in China's Shenzhen Special Economic Zone and has rich management experiences in international business. His research interest includes global strategy and organizational change, and he has published more than 30 referred articles, three books and three book chapters in global strategy with focus on core competence and capable organizations. 
Ronald Salazar (PhD from the University of Texas at Austin) is an Associate Professor of Management at University of Houston, Victoria. He has published in leading academic journals including the British Journal of Management, Journal of Applied Business Research, International Journal of Applied Business Research, and The Business Review. He has also authored numerous cases and book chapters. Dr. Salazar has extensive experience with strategic and tactical planning, management consulting, and the integration of the theoretical into practical business applications. For over twenty years, his consulting endeavors have focused on helping executives develop highly competitive organizations. E-mail: salazarr@uhv.edu (Corresponding author)

Joseph Ben-Ur (PhD from the University of Illinois) is a Professor of Marketing and Consumer Behavior at the University of Houston-Victoria. Prior to joining the UHV faculty, he held academic positions at several universities including the University of Wisconsin Milwaukee, the University of Alaska and DePaul University. Dr. Ben-Ur has published in several academic journals; among them are Management Science, Energy Economics, Psychology and Marketing, The European Journal of Marketing, Journal of Business and Society, and Journal of International Business and Economics. Dr. Ben-Ur is senior editor of the Journal of Political Marketing. E-mail: benurj@uhv.edu

\section{REFERENCES}

1. Atkinson, R D. (March 10, 2012). Assessing China's Efforts to Become an Innovation Society: A Progress Report, Testimony before the U.S.-China Economic and Security Review Commission, Information Technology and Innovation Foundation.

2. Bartlett, C. A. (1983). MNEs: Get off the Reorganization Merry-Go-Round. Harvard Business Review, March- April: 138-146.

3. Bartlett, C.A. \& Ghoshal S. (1986). Tap Your Subsidiaries for Global Reach. Harvard Business Review, 64(6): 87-94.

4. Beamish, P.W. (1993). The Characteristics of Joint Ventures in the People's Republic of China, Journal of International Marketing, 1(2): 29-48.

5. $\quad$ Castro-Gómez, S (2001). "Traditional vs. Critical Cultural Theory." Translated by F. González \& A. Moskowitz. Cultural Critique 49: 139-154.

6. Child, J. (1972). Organizational Structure, Environment and Performance: The role of Strategic Choice. Sociology, 6(1), 1-22.

7. Cohen, B.I. and Rugman, A.M. 1976. Risk reduction by international diversification. Journal of International Business Studies. Fall/Spring: 75-80.

8. Davidson, W.H. \& McFeteridge, D.J. 1985. Key Characteristics in the Choice of International Technology Transfer Mode. Journal of International Business Studies, 16(Summer), 5-22.

9. Deng, Z., Falvey, R, \& Blake, A. (2010). Swapping Market Access for Technology Spillovers? Tax Incentives and Foreign Direct Investment in China, Paper Presented at International Conference on Applied Economics. Accessed September 12, 2012, Retrieved from http://kastoria.teikoz.gr/icoae2/wordpress/wpcontent/uploads/articles/2011/10/016.pdf

10. Dongli, Z. (2013). The Revival of Vertical Integration: Strategic Choice and Performance Influences. Journal Of Management \& Strategy, 4(1), 1-14. doi:10.5430/jms.v4n1p1.

11. Doz, Y. \& Prahalad, C K. (1984). Patterns of Strategic Control within Multinational Corporations. Journal of International Business Studies, 15, 55-72.

12. Fan, D., Zhu, CJ, \& Nyland, C. (2012). Perceived Factors Affecting the Integration-Responsiveness Framework: An Analysis from Chinese Multinationals Operating in Australia, International Journal of Business and Management; 7(13), 27-39.

13. Fortier, D. \& El Hadrioui, B. (2012). Multicultural Managerial Competence: Understanding the Potential Contribution of Cultural Mediators. Paper presented at Annual Paris Business and Social Sciences Conference, Paris, France, July 12-13.

14. Gupta, A.K \& Govindarajan V. (1991). Knowledge Flows and The Structure of Control Within Multinational Corporations. Academy of Management Review, 16(4): 768-792.

15. Horkheimer, M. (1937) Traditionelle und Kritische Theorie. Frankfurt am Main: Fischer.

16. Jarillo, J. C. \& J. I. Martinez. (1990). Different Roles for Subsidiaries: The Case of Multinational Corporations in Spain. Strategic Management Journal, 11(7): 501-512. 
17. Johnson, V. (2012). What Makes Organizational Imprints Stick? Identity Persistence at the Paris Opera from Louis XIV to the French Revolution, Retrieved September 12, Retrieved from http://www.yale.edu/macmillan/transitionstomodernity/papers/Johnson_Paris_Opera.pdf

18. Kim, W.C. \& Hwang, P. 1992. Global Strategy and Multinational Entry Mode Choice. Journal of International Business Studies, 23, 1, 29-53.

19. Kogut, B., \& Singh, H. (1988). The Effect of National Culture on the Choice of Entry Mode. Journal of International Business Studies, 19: 411-430.

20. Krugman, P. (1991), Increasing Returns and Economic Geography, Journal of Political Economy, 99, 483499.

21. Laeven, L. \& Valencia, F. (2012). Systemic Banking Crises: A New Database, Retrieved September 12, Retrieved from http://www.imf.org/external/np/seminars/eng/2012/fincrises/pdf/ch2.pdf

22. McGregor, J. (2010). China's Drive for 'Indigenous Innovation': A Web of Industrial Policies, US Chamber of Commerce, Retrieved September 12, Retrieved from http://www.uschamber.com/sites/default/files/reports/100728chinareport 0.pdf

23. Mao, Yunshi (1997). Strategic Competition of Multinational Enterprises and Foreign Direct Investment, Publishing House of Zhongshan University.

24. Mjoen, H., and Tallman, S. (1997). Control and Performance in International Joint Ventures. Organization Science, 8(3), 257-274.

25. Robinson, W. T., Fornell, C., \& Sullivan, M. (1992). Are Market Pioneers Intrinsically Stronger Than Later Entrants?. Strategic Management Journal, 13(8), 609-624.

26. Root, F. (1987). Entry Strategies for International Markets. Lexington, MA: Lexington Books.

27. Salazar, R. J., Jifu, W., \& Oswald, S. (2011). A Model for Technology Adoption In China: Extending Caselli And Coleman. Journal of Applied Business Research, 27(4), 79-90

28. Snyder, Q.S. (2011): Unbound and Unbridled: Institutions and the Increasing Returns to Power, Retrieved September 12, http://www.bsos.umd.edu/gvpt/irworkshop/papers_fall11/UnboundandUnbridled.pdf

29. Southwest Economy 2005 (4). Publication of Federal Reserve Bank of Dallas.

30. Stopford, J. M., \& Wells, L. T. (1973). Managing The Multinational Enterprise. International Executive, 15(2), 9-11.

31. Taggart, J. H. (1996). An empirical evaluation of the C-C paradigm. SIBU Working Paper 96/6, University of Strathclyde.

32. Oliver E. Williamson (1985), The Economic Institutions of Capitalism: Firms, Markets, Relational Contracting - Business \& Economics, Free Press

33. White, R.E. \& Poynter, T.A. (1984). Strategies for Foreign-owned subsidiaries in Canada. Business Quarterly, 48(4), 59-69. 